\title{
Classification of Coronary Artery Bifurcation Lesions and Treatments: Time for a Consensus!
}

\author{
Yves Louvard, ${ }^{1 *} \mathrm{MD}$, Martyn Thomas, ${ }^{2}$ MD, Vladimir Dzavik, ${ }^{3} \mathrm{MD}$, David Hildick-Smith, ${ }^{4} \mathrm{MD}$, \\ Alfredo R. Galassi, ${ }^{5}$ MD, Manuel Pan, ${ }^{6}$ MD, Francisco Burzotta, ${ }^{7}$ MD, Michael Zelizko, ${ }^{8} \mathrm{MD}$, \\ Darius Dudek, ${ }^{9} \mathrm{MD}$, Peter Ludman, ${ }^{10} \mathrm{MD}$, Imad Sheiban, ${ }^{11} \mathrm{MD}$, Jens F. Lassen, ${ }^{12} \mathrm{MD}$, \\ Olivier Darremont, ${ }^{13} \mathrm{MD}$, Adnan Kastrati, ${ }^{14} \mathrm{MD}$, Josef Ludwig, ${ }^{15} \mathrm{MD}$, Ioannis lakovou, ${ }^{16} \mathrm{MD}$, \\ Philippe Brunel, ${ }^{17} \mathrm{MD}$, Alexandra Lansky, ${ }^{18} \mathrm{MD}$, David Meerkin, ${ }^{19} \mathrm{MD}$, Victor Legrand, ${ }^{20} \mathrm{MD}$, \\ Alfonso Medina, ${ }^{21} \mathrm{MD}$, and Thierry Lefèvre, ${ }^{1} \mathrm{MD}$
}

\begin{abstract}
Background: Percutaneous coronary intervention (PCI) of coronary bifurcation lesions remains a subject of debate. Many studies have been published in this setting. They are often small scale and display methodological flaws and other shortcomings such as inaccurate designation of lesions, heterogeneity, and inadequate description of techniques implemented. Methods: The aim is to propose a consensus established by the European Bifurcation Club (EBC), on the definition and classification of bifurcation lesions and treatments implemented with the purpose of allowing comparisons between techniques in various anatomical and clinical settings. Results: A bifurcation lesion is a coronary artery narrowing occurring adjacent to, and/or involving, the origin of a significant side branch. The simple lesion classification proposed by Medina has been adopted. To analyze the outcomes of different techniques by intention to treat, it is necessary to clearly define which vessel is the distal main branch and which is (are) the side branche(s) and give each branch a distinct name. Each segment of the bifurcation has been named following the same pattern as the Medina classification. The classification of the techniques (MADS: Main, Across, Distal, Side) is based on the manner in which the first stent has been implanted. A visual presentation of PCI techniques and devices used should allow the development of a software describing quickly and accurately the procedure performed. Conclusion: The EBC proposes a new classification of bifurcation lesions and their treatments to permit accurate comparisons of well described techniques in homogeneous lesion groups. 2008 Wiley-Liss, Inc.
\end{abstract}

Key words: bifurcation lesions; QCA; classification of bifurcation lesions; classification of treatments

${ }^{1}$ Institut Cardiovasculaire Paris Sud, Massy, France

${ }^{2} \mathrm{BCIS}$, Kings College Hospital, London, United Kingdom

${ }^{3}$ University Health Network, University of Toronto, Canada

${ }^{4}$ Brighton and Sussex University Hospitals, NHS Trust, Brighton, United Kingdom

${ }^{5}$ Cardiac Catheterization and Interventional Cardiology Unit, Clinical Division of Cardiology, Ferrarotto Hospital, University of Catania, Catania, Italy

${ }^{6}$ Servicio de Cardiología, Reina Sofia Hospital, Córdoba, Spain

${ }^{7}$ Institute of Cardiology, Catholic University of the Sacred Heart, Rome, Italy

${ }^{8}$ Department of Cardiology, Institute for Clinical and Experimental Medicine, Prague, Czech Republic

${ }^{9}$ Department of Interventional Cardiology, Institute of Cardiology, Jagiellonian University Medical College, Krakow, Poland

${ }^{10}$ Queen Elizabeth Hospital, University Hospital Birmingham Trust, Birmingham, United Kingdom

${ }^{11}$ Interventional Cardiology Department, University of Torino, San Giovanni Battista Hospital, Torino, Italy

${ }^{12}$ Department of Cardiology, Aarhus University Hospital, Skejby, Denmark

${ }^{13}$ Interventional Cardiology Department, Clinique Saint-Augustin, Bordeaux, France
${ }^{14}$ Interventional Cardiology, Department of Cardiovascular Diseases, German Heart Center, Munich, Germany

${ }^{15}$ Medizinische Klinik 2, Erlangen, Germany

${ }^{16}$ Army Hospital of Thessaloniki and Blue Cross Heart Center, Thessaloniki, Greece

${ }^{17} \mathrm{USCl}$, Nouvelles Cliniques Nantaises, Nantes, France

${ }^{18}$ Angiographic Core Laboratory, Columbia University Medical Center, Cardiovascular Research Foundation, New York, New York

${ }^{19}$ Department of Cardiology, Hadassah Hebrew University Medical Center, Jerusalem, Israel

${ }^{20}$ Service de Cardiologie, CHU de Liège, Liège, Belgium

${ }^{21}$ Department of Cardiology, University Hospital Dr. Negrin, Las Palmas, Spain

*Correspondence to: Dr. Yves Louvard; Institut Cardiovasculaire Paris Sud, Massy, France. E-mail: y.louvard@icps.com.fr

Received 18 June 2007; Revision accepted 20 June 2007

DOI $10.1002 / \mathrm{ccd} .21314$

Published online 2 November 2007 in Wiley InterScience (www. interscience.wiley.com). 


\section{INTRODUCTION}

Percutaneous coronary intervention (PCI) of bifurcation disease remains a challenge in terms of procedural success rate as well as long term major cardiac events (MACE), target lesion revascularization (TLR), restenosis, and stent thrombosis. The optimal technique with drug-eluting stents (DES) is still the subject of considerable debate because relevant randomized studies [1-3] are scarce and small scale. Hence, they are not able to provide real statistical value, often provide no clear definitions of the techniques used and often merely compare stent deployment in the main vessel versus the two branches by means of several heterogeneous techniques. Furthermore, patients with long sidebranch lesions were systematically excluded from the randomized trials [4]. Registries, though available in greater numbers [5-21], are of variable quality and use different lesion classification systems, quantitative coronary angiography (QCA) measurements performed in unclear technical conditions, with identical technical strategies bearing different names or different techniques grouped under a single name. Other than the comparison between stent deployment in one versus two branches, a meta-analysis of these various reports has proven quite impossible. Consequently, there is a need for a simplified and universal classification of lesions, specific guidelines for coronary bifurcational QCA, an accurate definition of each of the various techniques used, and a precise classification to facilitate their description.

The European Bifurcation Club (EBC) was founded in 2004 in order to devise a common terminology for the description and treatment of bifurcation lesions and to exchange ideas on the clinical, technical, and fundamental aspects of the specific treatment strategies implemented in this setting. The present article is aimed at fulfilling the four requirements expressed earlier.

\section{DEFINITION AND CLASSIFICATION OF CORONARY BIFURCATION LESIONS}

Many definitions have been proposed for a coronary bifurcation stenosis. Here are some definitions proposed by the authors of this study: A lesion located in a bifurcation point? A lesion located in a bifurcation point with a side branch $>2 \mathrm{~mm}$ in diameter? A lesion located in a bifurcation point with a side branch that you do not want to lose? A lesion located in a bifurcation point with a side branch that needs to be treated? The differences are subtle but the consequences for inclusion in a database may be important.

As a definition we propose that a bifurcation lesion is "a coronary artery narrowing occurring adjacent to, and/or involving, the origin of a significant side branch." A significant SB is a branch that you do not want to lose in the global context of a particular patient (symptoms, location of ischemia, branch responsible for symptoms or ischemia, viability, collateralizing vessel, left ventricular function, and so forth).

All the previously published classifications of coronary bifurcation lesions require significant efforts of memorization [22-26]. They describe relatively relevant anatomical configurations. The classification by Medina et al. [27] is straightforward and does not need to be memorized even though it provides all the information contained in the others (Fig. 1). It consists in recording any narrowing in excess of $50 \%$ in each of the three arterial segments of the bifurcation in the following order, proximal main vessel (PMV), distal main branch (DMV), and SB: 1 is used to indicate the presence of a significant stenosis and 0 the absence of stenosis. The three figures are separated by commas. It has been suggested that the Medina classification should also contain information on the lesion length, especially for the SB, or presence of calcifications. Moreover, the angle between the two branches has been recently shown to have a significant impact on certain techniques and on the clinical outcome at follow-up [28]. However, apart from the fact that the presence of quantifiable variables would be recorded under "yes" or "no," the addition of these 3 parameters and possibly others (eccentric location of the main branch lesion, TIMI flow, and so on) would negate the simplicity of the Medina classification. The only parameter which is currently being debated is the lesion

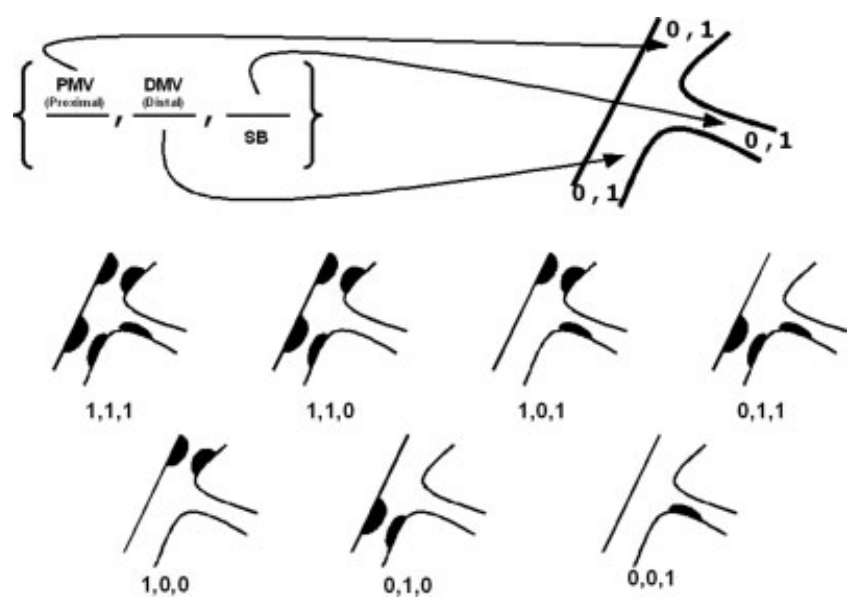

Fig. 1. Medina classification of coronary bifurcation lesions: 1 is used to indicate the presence of stenosis and 0 the absence of stenosis in each of the three segments. The three digits are separated by commas, PMV first followed by distal branches in order of importance (see denomination of lesions). 
length in the SB, which could have a significant impact at least on the technique used and the acute results [29]. This classification does not replace QCA measurements, which remain indispensable. As a matter of fact, the question can be raised as to whether the Medina classification should be based on visual assessment or on the presence of $>50 \%$ stenosis in each of the three arterial segments as evidenced by adequate QCA measurement. A rigorous approach calls for the second option.

\section{QCA OF BIFURCATION LESIONS}

The coronary tree is an object of fractal geometry governed by Murray's law [30]. This law has been verified in human coronary arteries by intra vascular ultrasound [31]. The relation of the diameters between the PMVs and its two (or more) distal branches is: $\mathrm{PMV}=(\mathrm{DMV}+\mathrm{SB}) \times 0.67$. Generally, the bifurcation main vessel is still considered as a single segment with a single reference diameter function, which is inaccurate according to Murray's law. As a consequence, the PMV reference diameter is underestimated (and any lesion located in this segment is overestimated) whilst the reference diameter of the DMV just beyond the $\mathrm{SB}$ is overestimated (and any lesion in this segment underestimated). QCA of the SB poses a more complex problem because if the PMV is included in the automated design, the SB reference diameter at ostium level is grossly overestimated (and any potential lesion underestimated). If the $\mathrm{SB}$ is constructed from the ostium, in the presence of a proximal lesion, the reference function of this vessel is increasing in most cases, which is theoretically impossible and leads to an overestimation of lesions.

There are not many computer programs allowing analysis of all three segments of the bifurcation according to Murray's law. Using a conventional software, one may successively construct the PMV towards the DMV and then the PMV towards the SB while flagging off the irrelevant segment (DMV when analyzing the PMV, PMV when analyzing the DMV, PMV when analyzing the SB). This human intervention should be limited to obtaining a decreasing reference function. When analyzing the SB, the maximum distal diameter should on occasion be selected as the reference diameter.

Other important parameters to be included in the QCA assessment of bifurcations are as follows: TIMI flow in both branches, presence of calcifications (semiquantitative), uneven or ulcerated segments, concentric or eccentric location of the MV lesions as well as plaque position in relation to the SB (contra or ipso-lateral).
The most important parameter is the measurement of angles between the three segments (impact on prognosis). In the absence of three-dimensional image reconstruction [32], the best way to achieve reliable measurement of the angles between the various segments is to perform it in the angiographic view in which the foreshortening of the three segments is minimal. This is often the operator's working view. It has been suggested (Y. Louvard, TCT 2003) that the angle between the PMV and the SB may be called Angle A. The degree of this angle has an influence on the accessibility of the side branch, which is frequently the reason for initially stenting the SB. Angle B is between the two distal branches (impact on the risk of SB occlusion during $\mathrm{MB}$ stenting [33]. Angle $\mathrm{C}$ is between the PMV and the DMV. It has been shown to be related to the technical success rate of the Frontier dedicated stent. Measurement of the first two angles seems essential. Dedicated coronary bifurcation computer programs are currently being investigated [34].

\section{DESIGNATION OF CORONARY BIFURCATION LESIONS}

QCA measurement, lesion classification, and subsequent accurate definition of the technique used require clear designation of the side branch prior to commencing treatment. Designation of bifurcation lesions is crucial in the description of implemented techniques. Indeed, some of these techniques have "inverted" variants with specific technical requirements, such as deployment of a PMV stent towards the smallest distal branch across the DMV. A change in the definition of the SB results in a change of the technique from "standard" to "inverted."

What defines the SB and the DMV in a coronary bifurcation? There are several viewpoints. The "nosological" approach: The left anterior descending artery (LAD), the circumflex coronary artery (Circ.), and the posterior descending artery (PDA) are always the DMV in relation to the diagonal (Dg), the septal (S), and marginal $(\mathrm{Mg})$ branches and to the postero-lateral artery (PLA). Though this is often true for the LAD, the marginal branches are generally larger and/or longer than the distal circumflex artery. The PLA may also be larger than the PDA.

The QCA viewpoint: the largest of the distal branches is the DMV. This corresponds to the most frequently applied technical strategy which consists of deploying the stent from the PMV across the smallest distal branch towards the largest. This, however, may be inconsistent with the real physiological significance of this large branch (small territory, distal occlusion, infarction sequelae, and so on). 

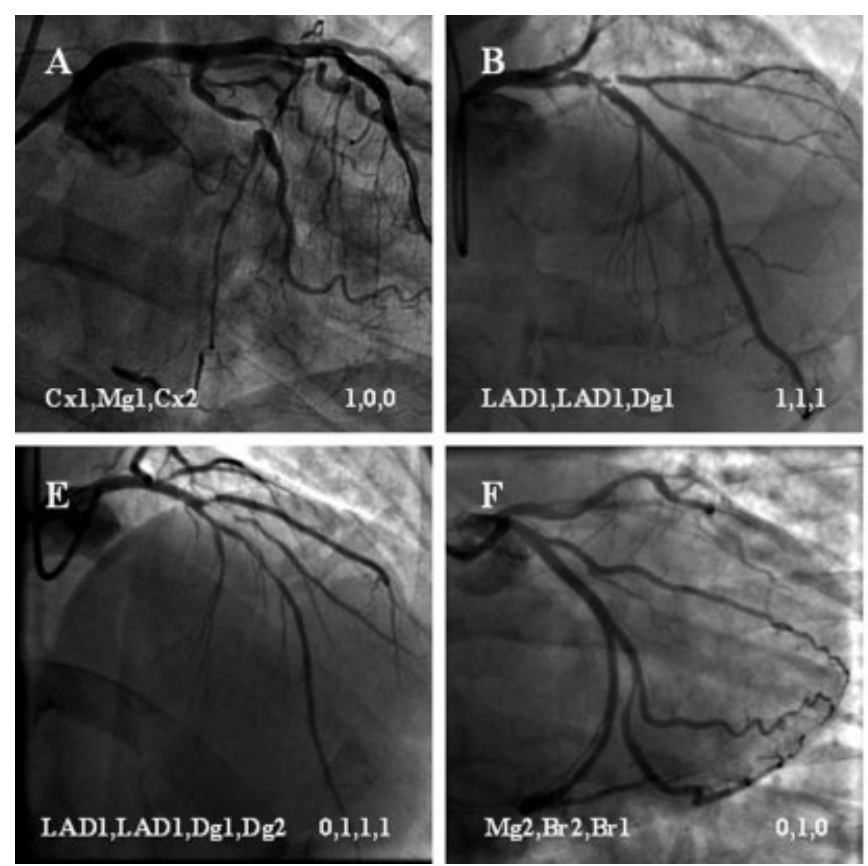

Fig. 2. Examples of coronary bifurcation lesions denomination. A: Tight stenosis in the proximal circumflex artery, the mid circumflex artery was considered as the SB. B: Complex lesion in the proximal left anterior descending artery (PMV and DMV), the diagonal branch is the SB. C: A tight stenosis in the DMV (2nd segment of the right coronary artery), the SB is a right marginal branch. D: a trifurcation lesion of the left main

It seems reasonable to allow the operator to determine which branch should be considered the DMV. However, this decision must be made prior initiation of the procedure to allow for an intention-to-treat analysis, and must not be motivated only by the degree of technical difficulty. This will avoid heterogeneous definitions whereby minor branches would be analyzed as main branches. We propose the following notations: abbreviated name (or number) of the PMV, abbreviated name of the DMV, abbreviated name of the SB. In the presence of two SB's, another abbreviation will be added, the less important of the two SB being the last abbreviation (Fig. 2).

\section{CLASSIFICATION OF BIFURCATION LESIONS TREATMENT TECHNIQUES}

A family classification system facilitates the description of techniques by listing only the variants of each individual technique. Few classifications have been proposed [26]. Some of them are of merely historical interest due to the increase in the number of techniques currently in use. The ICPS classification reported first in 1996 [24] was further expanded with the advent
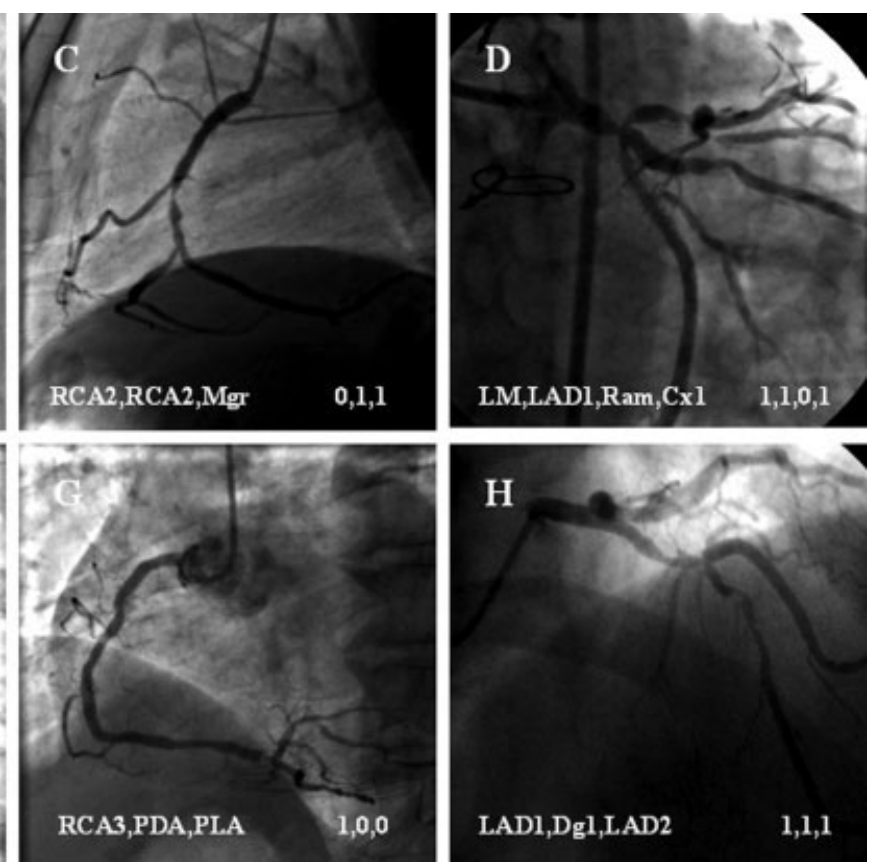

coronary artery, LAD is the DMV, Circumflex., and Ramus are the SB in order of importance. E: a trifurcation lesion, proximal LAD is the PMV and the DMV, 2 Diagonal branches are the SB. F: Bifurcation lesion in a 2nd Marginal branch, the lesion is in the 2nd branch of the Marginal (most distal). G: in this case the PDA was chosen as the DMV. H: in this case the first Diagonal was chosen as the DMV.

of new techniques in 2004 [33]. However, this classification has now become obsolete. Achieving the simplicity and exhaustiveness required in any new classification seems a daunting task. As regards simplicity, the usual digits and letters do not seem adequate as they require memorization. The introduction of visual elements such as stent position in the bifurcation may be simpler. Afterwards, these elements may be identified by a number or appear in a visual CRF. Keeping an open classification is a realistic objective provided that all potential scenarios are anticipated. Several classification methods have been considered. One of these methods based upon the number of vessels stented and the order in which stents are implanted does not take into account the complexity of the techniques described. Another classification can be made according to the final aspect of stents in the coronary bifurcation but the order in which stents are implanted and the inherent technical difficulties (stenting through stent struts) are not accounted for, and neither are the potential impact on the outcome [24], or the possibility of implanting the second stent only when necessary (provisional SB strategy). Following the implantation of the first stents, technical options for any subsequent 


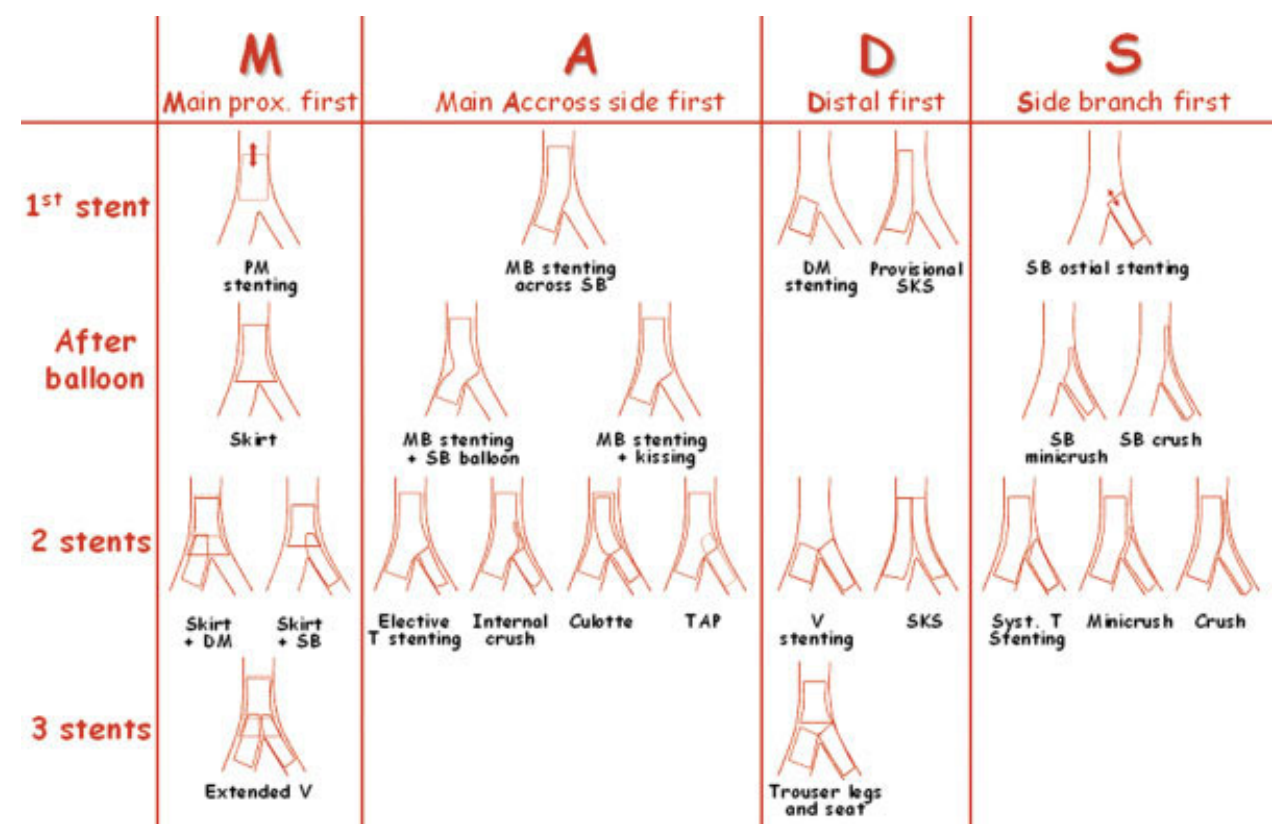

Fig. 3. MADS classification of techniques (standard techniques). In "M" family the "Skirt" technique was described with use of a stent manually crimped onto two balloons, but it is currently used with a dedicated stent (DEVAX). In the "A" family the T stenting technique seems similar to that of the " $S$ " family, but here the MV stent is deployed first allowing provisional (Elective) and possibly better deployment of the SB stent. The internal Crush was named first Reverse Crush. The "TAP" stenting figure has also been named "Exaggerated $Y$ " (Buchbinder). In the "S" family, though the intention is differ-

stent deployment are increasingly limited. We suggest a classification taking into account initial stent deployment, which often corresponds to a technical strategy related to the importance of the vessel treated first. For example, stenting the PMV first, towards the DMV across the SB corresponds to the strategy of provisional SB stenting. The following steps of the procedure, either part of a preselected strategy or prompted by events, which consists of placing a second stent constitute the variants of this technique. We have strived to include all potential technical strategies by describing four ways of beginning the procedure (Fig. 3). However, we only mention techniques that have been published, reported or described during personal communications (EBC meeting). The classification into four families corresponds to the suggested acronym "MADS" as shown in Figure 3. Each drawing represents final stent placement upon procedure completion: the drawings on the first line may represent the beginning and the end of the procedure as well as some of the drawings on the third line (simultaneous double stenting).

The first family ( $M$ for Main) starts by stent implantation in the PMV relatively close to the carina. This potentially significant technical detail may be included in the QCA analysis. This initial step may be followed ent between Minicrush and Modified $\mathrm{T}$ stenting described by Colombo, in practice when treating a patient it is very difficult to distinguish between the two stent figures (someone suggested that in modified $T$ stenting the secondary access to the SB for kissing balloon inflation should be achieved through the lumen of the SB stent, instead of one of the most proximal stent cells, which is possible in a bench but hardly feasible in patients. [Color figure can be viewed in the online issue, which is available at www.interscience.wiley.com.]

by the opening of the stent towards both branches (SKIRT technique) $[35,36]$, with subsequent successive or simultaneous stent placement in one or both distal branches.

The second family ( $A$ for Across) starts with the stenting of the PMV to the DMV across the SB. This may be the first and the last step of the procedure but may also be followed by the opening of a stent cell with or without kissing balloon inflation towards the SB [37], and if necessary by the delivery of a second stent in the SB in a T [38], TAP (T And small Protrusion) (Burzotta, personal communication), Culotte [3941], or Internal Crush configuration [42,43].

The third family ( $D$ for Distal) involves the distal branches and historically starts with simultaneous stent placement at the ostium of both distal branches (V stenting) [44,45]. A recent variant consists in creating a new carina (the length of which can be determined by QCA analysis) by stent implantation in the proximal segments (Simultaneous Kissing Stent or SKS) $[46,47]$. A V stenting configuration can also be achieved by successive delivery of the stents; a "provisional" variant of SKS consists in delivering a single distal stent by inflating a balloon in the other branch (Debinsky, personal communication). 


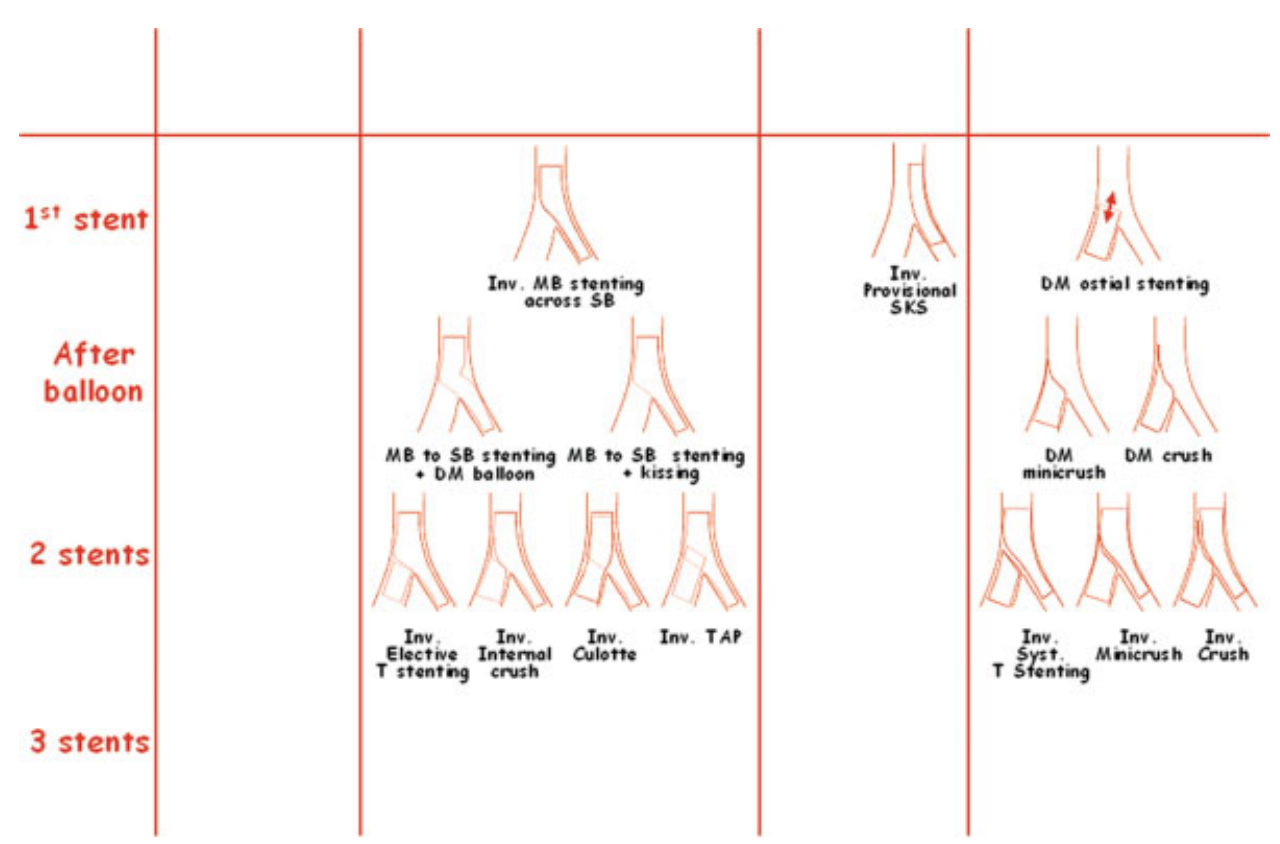

Fig. 4. MADS classification of techniques: Inverted techniques. These are the theoretically possible "inverted" techniques, the published and most frequently used being the Inverted Crush and Inverted Culotte. This denomination, inverted, is highly dependent on the choice of the DMV. [Color figure can be viewed in the online issue, which is available at www. interscience.wiley.com.]

The fourth family ( $S$ for Side) involves strategies where the side branch is stented first, either at ostium level [48], or with relatively pronounced protrusion into the PMV (as measured by QCA) $[49,50]$. The SB stent may be crushed with a balloon inflated in the MV or a second stent may be deployed in the MV across the SB.

This classification does not accurately reflect the relentless imagination of interventional cardiologists since some of these techniques have been inverted (- and not reversed by consensus and under the impetus of A. Colombo) as follows: in "A" family by implanting the First stent from the PMV to the SB, by stenting SB with protrusion in the PMV without crush in the " $D$ " family or by implanting the first stent in the DMV followed by stenting from PMV to SB in "S" family (Fig. 4).

All dedicated stents currently in use or under assessment are implanted utilizing the techniques described in the MADS classification. The DEVAX stent is deployed by means of a SKIRT technique. Stent delivery systems allowing permanent access to both distal branches are used with the provisional side branch stenting strategy of the A Family (Frontier Boston, Twinrail Invatec, Nile Minvasys, and so on). An inverted Culotte technique is used for deployment of the TRYTON stent and systematic $\mathrm{T}$ stenting for the Capella stent.

\section{DEFINITION AND DENOMINATION OF CORONARY BIFURCATION LESION TREATMENT TECHNIQUES}

Techniques used for treatment of coronary bifurcation lesions must be accurately defined for at least two reasons. First, to compare various techniques with an intention-totreat analysis, with respect to success rate, procedure duration, X-ray exposure, volume of contrast media used, and long-term follow-up. Second, impact of elaborate techniques on the outcome can be major (for instance, the threefold decrease in TVR associated with the Crush stenting technique with final kissing balloon inflation) [12].

Many interventional cardiologists may fail to identify their favorite technique in the earlier classification. However, the combination of this classification with a number of wire, balloon, and atherectomy techniques accounts for all variants already reported or published [51-53]. We have decided to retain the initial denomination given to each individual technique, or, in the presence of several denominations, to select the most straightforward.

In the A family, Pan et al. described several variants to the strategy of "MV stenting across SB" consisting of protecting the SB during main branch stenting or in predilating the SB prior to MV stenting [54]. The provisional stenting techniques described above may or may not be followed by kissing balloon inflation, which constitutes several variants. In the D family, 


\begin{tabular}{|c|c|c|c|c|c|c|c|c|c|c|c|c|c|}
\hline & INTENTION & Step 1 & Step 2 & Step 3 & Step 4 & Step 5 & Step 6 & Step 7 & Step 8 & Step 9 & Step 10 & FINAL & TECHNIQUE \\
\hline 1 & & & & & & & & & & & & & $\begin{array}{l}\text { Elective T } \\
\text { stenting }\end{array}$ \\
\hline 2 & & & & & & & & & & & & & Step Crush \\
\hline 3 & & & $\downarrow$ & & & & & & & & & & SKS \\
\hline
\end{tabular}

Fig. 5. Toward an interactive bifurcation treatments e-CRF: Three examples of detailed descriptions of bifurcation treatment techniques using a graphic interface. Specifications of devices used (size, diameter, pressures etc.) would be added. [Color figure can be viewed in the online issue, which is available at www.interscience.wiley.com.]

placement of two stents in both distal branches may theoretically be carried out in two stages, thus generating variants. The $\mathrm{S}$ family comprises the largest number of techniques. The Crush technique has generated the largest number of variants. The classical Crush technique [55] consists in the partial deployment of the SB stent in the PMV; the undeployed stent placed in the MV is subsequently deployed after removal of the SB wire. The main disadvantage of this technique is that it requires the use of a guiding-catheter at least 7 Fr in diameter. The classical Crush technique may be improved by final kissing balloon inflation [12], while other operators prefer to inflate a high-pressure balloon toward the SB before performing kissing balloon inflation (Airoldi, personal communication). The techniques known as "Step Crush" (Sheiban, personal communication) or "Balloon Crush" [56] are identical and consist of crushing the SB stent with a balloon before advancing and deploying the MV stent. The techniques named "modified balloon Crush" [57], "double kissing crush" [58],"sleeve technique" [59] are other variants of the Crush technique. When the SB stent is crushed on a short segment, the best denomination seems to be "minicrush" as described by Galassi et al. [60] compared to modified $\mathrm{T}$ stenting as described by Kobayashi et al. [49].

\section{TOWARDS AN E-CRF DEDICATED TO CORONARY BIFURCATION LESIONS}

Describing a technique thoroughly in a case report form is rather tricky. However, the recording of each successive step in a computer file with an internet interface including the MADS classification and all the PCI devices seems feasible (Fig. 5). This would allow the collection of thousands of coronary bifurcation procedures in a database as well as the comparison of numerous well-described techniques in preparation for very promising potential randomised comparisons.

\section{CONCLUSIONS}

Two major randomized trials comparing one or two stents in the treatment of coronary bifurcations are either completed or ongoing (Nordic Bifurcation Study and $\mathrm{BBC}$ 1). Further trials in such a context appear unnecessary. One difficulty of these types of trial is that the treatment group including two stents is heterogeneous and the techniques used may have very different mid-term outcomes.

Randomized studies comparing techniques (two by two) display shortcomings in the areas of technique selection, nature of lesions treated, and financial cost of multiple studies.

The setting up of a large database allowing the identification of the most efficient techniques for each lesion type requires a clear definition of lesions, guidelines for QCA of bifurcation lesions, as well as denomination, classification, and accurate description of the techniques used. This is one of the self-assigned missions of the EBC. The purpose of this article is to fulfil this mission by proposing a glossary of bifurcation lesions. 


\section{ACKNOWLEDGMENTS}

Thanks to Dr R. Kornowski for the acronym "MADS." The authors thank Mrs Catherine Dupic for the preparation of the manuscript.

\section{REFERENCES}

1. Colombo A, Moses JW, Morice MC, Ludwig J, Holmes DR Jr, Spanos V, Louvard Y, Desmedt B, Di Mario C, Leon MB. Randomized study to evaluate sirolimus-eluting stents implanted at coronary bifurcation lesions. Circulation 2004;109:1244-1249.

2. Pan M, de Lezo JS, Medina A, Romero M, Segura J, Pavlovic D, Delgado A, Ojeda S, Melian F, Herrador J, Urena I, Burgos L. Rapamycin-eluting stents for the treatment of bifurcated coronary lesions: A randomized comparison of a simple versus complex strategy. Am Heart J 2004;148:857-864.

3. Steigen TK, Maeng M, Wiseth R, Erglis A, Kumsars I, Narbute I, Gunnes P, Mannsverk J, Meyerdierks O, Rotevatn S, Niemela M, Kervinen K, Jensen JS, Galloe A, Nikus K, Vikman S, Ravkilde J, James S, Aaroe J, Ylitalo A, Helqvist S, Sjogren I, Thayssen P, Virtanen K, Puhakka M, Airaksinen J, Lassen JF, Thuesen L; Nordic PCI Study Group. Randomized study on simple versus complex stenting of coronary artery bifurcation lesions: The Nordic bifurcation study. Circulation 2006;114:1955-1961.

4. Dzavik V. Progress in percutaneous management of coronary bifurcation lesions. Minerva Cardioangiol 2005;53:379-401.

5. Pan M, Suarez de Lezo J, Medina A, et al. Simple and complex stent strategies for bifurcated coronary arterial stenosis involving the side branch origin. Am J Cardiol 1999;83:1320-1325.

6. Yamashita T, Nishida T, Adamian MG, Briguori C, Vaghetti M, Corvaja N, Albiero R, Finci L, Di Mario C, Tobis JM, Colombo A. Bifurcation lesions: two stents versus one stent-immediate and follow-up results. J Am Coll Cardiol 2000;35:1145-1151.

7. Sheiban I, Albiero R, Marsico F, et al. Immediate and long-term results of " $\mathrm{T}$ " stenting for bifurcation coronary lesions. Am J Cardiol 2000;85:1141-1144, A9.

8. Al Suwaidi J, Berger PB, Rihal CS, et al. Immediate and longterm outcome of intracoronary stent implantation for true bifurcation lesions. J Am Coll Cardiol 2000;35:929-936.

9. Anzuini A, Briguori C, Rosanio S, et al. Immediate and long-term clinical and angiographic results from Wiktor stent treatment for true bifurcation narrowings. Am J Cardiol 2001;88:1246-1250.

10. Gobeil JF, Lefevre T, Guyon P, Louvard Y, Chevalier B, Dumas P, Glatt B, Loubeyre C, Royer T, Morice MC. Stenting of bifurcation lesions using the Bestent: A prospective dual-center study. Cathet Cardiovasc Intervent 2002;55:427-433.

11. Assali AR, Teplitsky I, Hasdai D, Rechavia E, Solodky A, Sela O, Butto N, Shor N, Fuchs S, Battler A, Kornowski R. Coronary bifurcation lesions: To stent one branch or both? J Invasive Cardiol 2004; 16:447-450.

12. Ge L, Airoldi F, Iakovou I, Cosgrave J, Michev I, Sangiorgi GM, Montorfano M, Chieffo A, Carlino M, Corvaja N, Colombo A. Clinical and angiographic outcome after implantation of drug-eluting stents in bifurcation lesions with the crush stent technique: Importance of final kissing balloon post-dilation. J Am Coll Cardiol 2005;46:613-620.

13. Hoye A, van Mieghem CA, Ong AT, Aoki J, Rodriguez Granillo GA, Valgimigli M, Tsuchida K, Sianos G, McFadden EP, van der Giessen WJ, de Feyter PJ, van Domburg RT, Serruys PW. Percutaneous therapy of bifurcation lesions with drug-eluting stent implantation: The Culotte technique revisited. Int J Cardiovasc Intervent 2005; 7:36-40.
14. Assali AR, Assa HV, Ben-Dor I, Teplitsky I, Solodky A, Brosh D, Fuchs S, Kornowski R. Drug-eluting stents in bifurcation lesions: To stent one branch or both? Catheter Cardiovasc Interv 2006;68:891-896.

15. Hoye A, Iakovou I, Ge L, van Mieghem CA, Ong AT, Cosgrave J, Sangiorgi GM, Airoldi F, Montorfano M, Michev I, Chieffo A, Carlino M, Corvaja N, Aoki J, Rodriguez Granillo GA, Valgimigli M, Sianos G, van der Giessen WJ, de Feyter PJ, van Domburg RT, Serruys PW, Colombo A. Long-term outcomes after stenting of bifurcation lesions with the "crush" technique: predictors of an adverse outcome. J Am Coll Cardiol 2006; 47:1949-1958.

16. Ge L, Iakovou I, Cosgrave J, Agostoni P, Airoldi F, Sangiorgi GM, Michev I, Chieffo A, Montorfano M, Carlino M, Corvaja N, Colombo A. Treatment of bifurcation lesions with two stents: One year angiographic and clinical follow up of crush versus $\mathrm{T}$ stenting. Heart 2006;92:371-376.

17. Brunel P, Lefevre T, Darremont O, Louvard Y. Provisional Tstenting and kissing balloon in the treatment of coronary bifurcation lesions: Results of the French multicenter "TULIPE" study. Catheter Cardiovasc Interv 2006;68:67-73.

18. Lefèvre T, Morice MC, Sengottuvel G, Kokis A, Monchi M, Dumas P, Garot P, Louvard Y. Influence of technical strategies on the outcome of coronary bifurcation stenting. EuroIntervention 2005;1:31-37.

19. Darremont O, Brunel P, Lefèvre T, Balcells J, Leymarie JL, Bressollette E, Fisher B, Leurent B, Louvard Y, Morice MC. Provisional T-stenting strategy using Paclitaxel-eluting stent for coronary bifurcation lesion treatment. The surf study. Am J Cardiol 2005;96(Suppl 7A):83H.

20. Airoldi F, Colombo A, Michev L, Briguori C, Chieffo A, Iakovou I, Ge L, Carlino M, Sangiorgi GM, Vitrella G, Stankovic G, Montorfano M. Sirolimus eluting stents implantation in bifurcational coronary artery lesions utilizing the 'Crush' Technique: Immediate and mid term outcome. JACC 2005;45:(3 Suppl A).

21. Rux S, Sonntag S, Schulze R, Rau M, Weber F, Muhling H, Cioppa A, Kleber FX; BISCOR Investigators. Acute and longterm results of bifurcation stenting (from the Coroflex Registry). Am J Cardiol 2006;98:1214-1217.

22. Koller P, Safian RD. Bifurcation Stenosis in Manual of Interventional Cardiology, Physician's Press 1996:229-241.

23. Topol EJ. Textbook of Interventional Cardiology, 3rd ed. Philadelphia: W.B. Saunders; 1999. p 1058.

24. Lefèvre T, Louvard Y, Morice MC, et al. Stenting of bifurcation lesions: Classification, treatments, and results. Catheter Cardiovasc Interv 2000;49:274-283.

25. Klein LW. The bifurcation lesion: more evidence that a new lesion classification system should be widely adopted. Catheter Cardiovasc Interv 2002;55:434-435.

26. Movahed MR, Stinis CT. A new proposed simplified classification of coronary artery bifurcation lesions and bifurcation interventional techniques. J Invasive Cardiol 2006;18:199-204.

27. Medina A, Suarez de Lezo J, Pan M. A new classification of coronary bifurcation lesions. Rev Esp Cardiol 2006;59:183.

28. Dzavik V, Kharbanda R, Ivanov J, Ing DJ, Bui S, Mackie K, Ramsamujh R, Barolet A, Schwartz L, Seidelin PH. Predictors of long-term outcome after crush stenting of coronary bifurcation lesions: importance of the bifurcation angle. Am Heart $\mathrm{J}$ 2006; $152: 762-769$.

29. Furukawa, et al. Intravascular ultrasound predictors of side branch occlusion in bifurcation lesions after percutaneous coronary intervention. Cir J 2005;69:325-330.

30. Zhou Y, Kassab GS, Molloi S. On the design of the coronary arterial tree: A generalization of Murray's law. Phys Med Biol 1999;44:2929-2945. 
31. Finet G, Gilard M. Lessons from IVUS in bifurcation lesions. Available at www.bifurc.net.

32. Schlundt C, Kreft JG, Fuchs F, Achenbach S, Daniel WD, Ludwig J. Three-dimensional on-line reconstruction of coronary bifurcated lesions to optimize side-branch stenting. Catheter Cardiovasc Interv 2006;68:249-253.

33. Louvard Y, Lefèvre T, Morice MC. Percutaneous coronary intervention for bifurcation coronary disease. Heart 2004;90:713722.

34. Goktekin O, Kaplan S, Dimopoulos K, Barlis P, Tanigawa J, Vatankulu MA, Koning G, Tuinenburg JC, Mario CD. A new quantitative analysis system for the evaluation of coronary bifurcation lesions: Comparison with current conventional methods. Catheter Cardiovasc Interv 2007;69:172-180.

35. Alberti A, Missiroli B, Nannini C. "Skirt" technique for coronary artery bifurcation stenting. J Invasive Cardiol 2000;12:633636.

36. Kobayashi Y, Colombo A, Adamian M, et al. The skirt technique: A stenting technique to treat a lesion immediately proximal to the bifurcation [pseudobifurcation]. Catheter Cardiovasc Interv 2000;51:347-351.

37. Ormiston JA, Webster MW, Ruygrok PN, et al. Stent deformation following simulated side-branch dilatation: a comparison of five stent designs. Catheter Cardiovasc Interv 1999;47:258-264.

38. Lefèvre T, Louvard Y, Morice MC, Loubeyre C, Piéchaud JF, Dumas P. Stenting of bifurcation lesions: A rational approach. J Interven Cardiol 2001;14:573-586.

39. Khoja A, Ozbek C, Bay W, et al. Trouser-like stenting: A new technique for bifurcation lesions. Cathet Cardiovasc Diagn 1997; 41:192-196.

40. Di Mario C, Colombo A. Trousers-stents. How to choose the right size and shape. Cathet Cardiovasc Diagn 1997,41:197-199.

41. Chevalier B, Glatt B, Royer T, et al. Placement of coronary stents in bifurcation lesions by the "culotte" technique. Am J Cardiol 1998;82:943-949.

42. Sianos G, Vaina S, Hoye A, Serruys PW. Bifurcation stenting with drug eluting stents: Illustration of the Crush technique. Catheter Cardiovasc Interv 2006;67:839-845.

43. Porto I, van Gaal W, Banning A. "Crush" and "reverse crush" technique to treat a complex left main stenosis. Heart 2006;92:1021.

44. Colombo A, Gaglione A, Nakamura S, et al. "Kissing" stents for bifurcation coronary lesion. Cathet Cardiovasc Diagn 1993; 30:327-330.

45. Schampaert E, Fort S, Adelman AG, et al. The V-stent: A novel technique for coronary bifurcation stenting. Cathet Cardiovasc Diagn 1996;39:320-326.

46. Sharma SK. Simultaneous kissing drug-eluting stent technique for percutaneous treatment of bifurcation lesions in large-size vessels. Catheter Cardiovasc Interv 2005;65:10-16.

47. Sharma SK, Choudhury A, Lee J, Kim MC, Fisher E, Steinheimer AM, Kini AS. Simultaneous kissing stents (SKS) tech- nique for treating bifurcation lesions in medium-to-large size coronary arteries. Am J Cardiol 2004;94:913-917.

48. Carrie D, Karouny E, Chouairi S, et al. "T"-shaped stent placement: A technique for the treatment of dissected bifurcation lesions. Cathet Cardiovasc Diagn 1996;37:311-313.

49. Kobayashi Y, Colombo A, Akiyama $T$, et al. Modified "T" stenting: A technique for kissing stents in bifurcational coronary lesion. Cathet Cardiovasc Diagn 1998;43:323-326.

50. Rizik DG, Klassen KJ, Dowler DA, Villegas BJ. Balloon alignment $\mathrm{T}$-stenting for bifurcation coronary artery disease using the sirolimus-eluting stent. J Invasive Cardiol 2006;18:454-460.

51. Nageh T, Kulkarni NM, Thomas MR. High-speed rotational atherectomy in the treatment of bifurcation-type coronary lesions. Cardiology 2001;95:198-205.

52. Karvouni E, Di Mario C, Nishida T, Tzifos V, Reimers B, Albiero R, Corvaja N, Colombo A. Directional atherectomy prior to stenting in bifurcation lesions: A matched comparison study with stenting alone. Catheter Cardiovasc Interv 2001;53:12-20.

53. Wong CB, Hardin S. A novel technique for coronary bifurcation lesions: Cutting balloons, drug-eluting stents and the kissing technique. J Invasive Cardiol 2005;17:108-110.

54. Pan M, Suarez de Lezo J, Medina A, Romero M, Segura J, Ramirez A, Pavlovic D, Hernandez E, Ojeda S, Adamuz C. A stepwise strategy for the stent treatment of bifurcated coronary lesions. Catheter Cardiovasc Interv 2002;55:50-57.

55. Colombo A, Stankovic G, Orlic D, Corvaja N, Liistro F, Airoldi F, Chieffo A, Spanos V, Montorfano M, Di Mario C. Modified T-stenting technique with crushing for bifurcation lesions: immediate results and 30-day outcome. Catheter Cardiovasc Interv 2003;60:145-151.

56. Lim PO, Dzavik V. Balloon crush: treatment of bifurcation lesions using the crush stenting technique as adapted for transradial approach of percutaneous coronary intervention. Catheter Cardiovasc Interv 2004;63:412-416.

57. Collins N, Dzavik V. A modified balloon crush approach improves side branch access and side branch stent apposition during crush stenting of coronary bifurcation lesions. Catheter Cardiovasc Interv 2006;68:365-371.

58. Chen SL, Ye F, Zhang JJ, Zhu ZS, Lin S, Shan SJ, Liu ZZ, Liu Y, Duan BX, Ge JB. DK crush technique: Modified treatment of bifurcation lesions in coronary artery. Chin Med J 2005;118: $1746-1750$.

59. Jim MH, Ho HH, Miu R, Chow WH. Modified crush technique with double kissing balloon inflation (sleeve technique): a novel technique for coronary bifurcation lesions. Catheter Cardiovasc Interv 2006;67:403-409.

60. Galassi AR, Colombo A, Buchbinder M, Grasso C, Tomasello SD, Ussia GP, Tamburino C. Long-term outcomes of bifurcation lesions after implantation of drug-eluting stents with the "MiniCrush Technique". Catheter Cardiovasc Interv 2007;70:976983. 